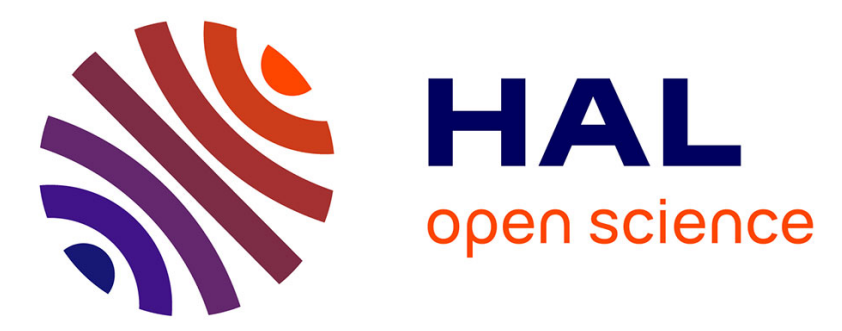

\title{
Introduction of frequency in France following the AZF accident
}

Clément Lenoble, Clarisse Durand

\section{To cite this version:}

Clément Lenoble, Clarisse Durand. Introduction of frequency in France following the AZF accident. Journal of Loss Prevention in the Process Industries, 2011, 24 (3), pp.227-236. 10.1016/j.jlp.2010.09.003 . ineris-00961759

HAL Id: ineris-00961759

https://hal-ineris.archives-ouvertes.fr/ineris-00961759

Submitted on 20 Mar 2014

HAL is a multi-disciplinary open access archive for the deposit and dissemination of scientific research documents, whether they are published or not. The documents may come from teaching and research institutions in France or abroad, or from public or private research centers.
L'archive ouverte pluridisciplinaire HAL, est destinée au dépôt et à la diffusion de documents scientifiques de niveau recherche, publiés ou non, émanant des établissements d'enseignement et de recherche français ou étrangers, des laboratoires publics ou privés. 


\title{
INTRODUCTION OF FREQUENCY IN FRANCE FOLLOWING THE AZF ACCIDENT
}

\author{
Clément LENOBLE ${ }^{*}$, Clarisse DURAND ${ }^{* *}$ \\ *INERIS, Accident risks division, Parc Technologique Alata BP2, F-60550 Verneuil-en-Halatte \\ ${ }^{* *}$ French Ministry of Ecology, Energy, Sustainable Development and the Sea, in charge of green technologies and \\ climate change negotiations - General directorate for risks prevention - Technological risks department - Grande \\ Arche de la Défense, F-92055 La Défense Cedex
}

In France, regulations regarding risk prevention and risk management are the result of more than 200 years of legislation, the evolution of which has often been consecutive to industrial accidents. Two years after the industrial accident of AZF (French initials for AZote Fertilisant), a new law was introduced on July 30, 2003 which described both prevention and repair of the damage caused by industrial and natural disasters. Since then, regulations have been made considerably tighter and the entire approach towards risk assessment has changed.

This law has developed very interesting tools for risk assessment and risk management (some of which are unique worldwide) and has initiated the use of frequency and probability in the French system. Better information to the public, stronger regulations, new methodology for safety reports, over-hauling of land-use planning and improved accident analysis are some of the mainstays of the law.

Regarding the introduction of frequencies and probabilities, as operators in France are free to choose the methodology of probability assessment, it is interesting to review the different methodologies used by operators, with their advantages and disadvantages.

In the light of these elements, France's National Institute of Industrial Environment and Risks (INERIS) has developed a methodology and tools aiming at helping both operators and authorities in the assessment of accident probabilities. This methodology focuses on installation characteristics. However, to deal with the lack of input data, tools are developed to build up available generic data regarding loss of containment, initiating events, safety barrier failure rates and root causes distributions.

Six years after the law of July 30, 2003 was passed, it is now possible to highlight the challenges and improvements brought about by the use of frequency and probability in risk assessment and policies developed as a result.

Keywords: AZF accident, probability, land-use planning, frequency, safety barrier, risk assessment, bow-tie, major accident

\section{LESSONS LEARNED FROM THE AZF ACCIDENT}

\subsection{The AZF accident}

The AZF factory belonged to Grande Paroisse (company detained by the TotalFinaElf group). At the time of the accident, the factory had 469 employees and a turnover of $100 \mathrm{M} €$. The factory, located $3 \mathrm{~km}$ from the centre of Toulouse (France - 750,000 people in 2001) and surrounded by a urban environment, produced fertilizers and a variety of chemical products.

The accident:

On September 21, 2001, at 10:17 AM, a huge detonation occurred in the nitrates area of the factory. The explosion was felt up to $75 \mathrm{~km}$ and was compared with an earthquake with an intensity of 3.4 on the Richter scale. An analysis of the consequences has led to estimate a TNT equivalent between 20 and 40 tons (Barthélémy et al., 2001). Windows broke up to $7 \mathrm{~km}$ and more than a thousand buildings were destroyed. 
After the explosion, important clouds of dust and red fumes containing oxides of nitrogen and ammonia were emitted.

Human and social consequences:

The accident left 31 people dead: 21 on the AZF site, 1 on a neighbouring factory and 9 in the vicinity of the site. Thousands of people were hospitalized (the Haute-Garonne Prefecture counted a total of 2,442 people as of 17 October 2001). The observed pathologies were mutilations, explosions of eardrums and pleura, bruises on spleen and liver, as well as fractures and wounds due to the blast wave, the falling-down of structures, broken glass or projections...

For thousands of people, the AZF accident was a major traumatic experience. Approximately 5,000 people consulted their general practitioner for acute post-traumatic stress during the first few days after the disaster (INVS, 2002). According to experts, these numbers are underestimated as they only take into account the individuals who sought medical care. The explosion was responsible for psychological problems (depression, anxiety...).

Environmental consequences:

The explosion destroyed some of the tanks containing ammonium nitrate and led to nitric acid leaks. Nitrogenous and ammonia releases polluted the Garonne river and entailed a fish mortality.

\section{Economic consequences:}

The AZF plant and the neighbouring factories were destroyed. About 1,300 firms (hiring approximately 21,000 people) were severely impacted by the accident (Dechy et al., 2004). The consequences were also dramatic on roads, and public buildings such as schools, colleges, hospitals... All in all, 25,000 dwellings were damaged, 11,180 of which severely (ARIA, 2007). More than a thousand were completely destroyed and more than 1200 families had to be rehoused in emergency after the disaster.

Insurance companies appraised the overall economic consequences up to 2 billions $€$ (ARIA, 2007).

\section{Emergency response:}

The external emergency plan was activated. A crisis centre was installed within the establishment. In total, 1,430 firemen and military men, 950 policemen, about 50 doctors, 32 nurses and 80 emergency medical technicians were called up (ARIA, 2007) .

A security perimeter was set up within a 500-meter radius. Many buildings and schools were evacuated. In the vicinity of the site, the air, railway and road traffic was entirely stopped.

Causes and circumstances of the accident:

Downgraded nitrates were stored in the shed 221 and were transported from different parts of the factory by subcontractors. At the time of the accident, that shed held between 300 and 400 tons of ammonium nitrates. According to the final legal expert report concluded that it was a chemical accident, due to an accidental combination of sodium dichloro-isocyanurate (SDIC - a product used for water treatment) and ammonium nitrate, causing the explosion. The operator has always disproved this theory.

Legal action:

Grande-Paroisse (as a legal entity) and the plant manager were charged with involuntary manslaughter and wounding.

The investigation gathered up to 140 policemen (judicial police and forensic and technical police laboratories) and 40 legal experts and lasted more than five years. The four-month trial ended on July 1, 2009 and the verdict is due on November 19, 2009.

\subsection{Deficiencies identified}

A thorough analysis of the accident has led to identify some deficiencies: 
- The safety report of the AZF factory did not take into account the downgraded ammonium nitrates store since it was considered as less dangerous (because of the smaller quantity stored). As a matter of fact, the safety report did not describe each possible accident scenario.

- Urbanization has considerably spread out in the vicinity of the site since the launching of the chemical activities. At the time of the accident, the chemical site was surrounded by business parks, hospitals, dwellings...

- People living around the industrial site were not perfectly aware of the potential risks of such an establishment.

- The ammonium nitrate storage facilities were not directly managed by the AZF company but by a subcontractor, whose knowledge of the products and the site could sometimes be incomplete. In addition to the 469 AZF employees, 80 people regularly worked on the site and were hired by nine different subcontractors.

As a consequence, the French government clearly stated the need to reassess the whole approach of risk analysis and land-use planning and also to improve the information to the public and the consideration of subcontractors.

\subsection{The Law of July 30, 2003 and its mainstays}

As a starting point, it is interesting to recall that in France, regulations regarding risk prevention and risk management are the result of more than 200 years of legislation, the evolution of which has often been consecutive to industrial accidents. The accident of the gunpowder factory that occurred in Paris in 1794 led to more than a thousand casualties. It brought about the imperial decree of October 15, 1810 about the factories that were sources of nuisances or risks. Three categories of factories were then defined (hazardous, insalubrious or causing inconvenience) and the first elements of land-use planning were enacted. This decree as well as the law of December 19, 1917 regarding "dangerous, unhealthy and inconvenient establishments" have established the fundamental rules for risk prevention and land-use planning in France.

The law of July 19, 1976 has modernized and updated the monitoring of classified installations according to the risks or nuisances that they generate. On the European level, the council directive 82/501/EEC on the major accident hazards of certain industrial activities - so called the Seveso directive - in 1982, laid the bases of a common policy for the prevention of major industrial accidents. The "Seveso II" directive, in 1996, introduced important changes and new concepts, such as safety management systems, emergency plans and land-use planning.

Six years after the publication of that directive and two years after the AZF accident, the law of July 30,2003 was introduced. It does not only deal with industrial disasters but also with natural disasters, as a response to floods that happened in France (caused by the rivers Somme, Gard and Hérault).

The law of July 30, 2003 regarding the prevention and repair of the damage caused by industrial and natural disasters, along with government actions, has enabled to focus on the following priorities:

- Increase of the number of inspectors and improvement of their training curriculum for a better regulation of the classified installations and for a more efficient control force: between 2001 and 2008, the number of inspectors increased by $40 \%$. In 2009, there are approximately 1,400 inspectors in France, including 400 to 500 specialized in Seveso establishments. Since 2005, the training curriculum for inspectors has also been expanded and improved. Within the first 6 to 8 months after the taking up of the position, inspectors have to attend two one-week courses about the legislation and regulation concerning industrial plants and specific regulations regarding water and air emissions, wastes, noise nuisances... Then, over the course of the first three years, nine general courses about industrial risks, crisis management, soil contamination, etc. have to be taken. For Seveso inspectors, more specialized courses about the safety report, safety management system, land-sue planning... are highly recommended. Moreover, the inspectorate has committed to inspecting every year each of the 2,000 high priority establishments (including the Seveso establishments) and every three years each of the 8,000 establishments at stake.

- Creation of interregional units specialised in technological risks: their role is to provide assistance on the assessment of the safety reports of Seveso establishments of several départements. It allows as well to harmonize the decisions and to ensure the circulation of best practices. 
- An Emergency Unit (CASU in French, standing for Cellule d'Appui aux Situations d'Urgence) has been created within France's National Institute of Industrial Environment and Risks. Experts can be mobilized 24-hour a day in case of an accident, in order to estimate the consequences and improve the emergency response.

- Development and improvement of the technological accidents database, named ARIA (on the website www.aria.developpement-durable.gouv.fr). It now makes available the details of more than 32,000 accidents and is continuously updated.

- A better information to the public about major industrial risks: The AZF accident highlighted the need of a better and more easily accessible information:

The law of July 30, 2003 provides the creation of a local information and dialogue committee (in French, a CLIC, standing for Comité Local d'Information et de Concertation) around the most dangerous establishments. Their role is to promote communication about risks between the public authorities, the operators and the civil society.

Besides, the permits of Seveso establishments are made available on the Internet, possibly with some publications of the results of inspections.

In October 2003, France ratified the UN/EEC Convention on the transboundary effects of industrial accidents. It aims at preventing industrial accidents that can have transboundary effects, preparing for and responding to them. This convention deals with exchanges of information in case of an accident and providing a mutual assistance.

Moreover, the law of July 30, 2003 lays upon sellers or landlords to inform potential purchasers or renters about the technological or the natural risks regarding the property.

- An improvement of the involvement of employees and subcontractors in risk prevention, so that each person on site gets the same level of knowledge. It is important to draw the attention to the importance of the human factor in accidents: in 2008, $61 \%$ of accidents were caused by organizational and human factors (Technological accidents inventory 2008). Under the law of July 30, 2003, all employees and subcontractors are kept informed through their representation in CLIC and in the working conditions, hygiene and safety committee (in French, CHSCT, standing for Comité d'Hygiène, de Sécurité et des Conditions de Travail).

- An improvement of the victims' compensation: The law of July 30, 2003 has described the notion of a technological disaster, that has to be inspected by official authorities. Within three months after the disaster was officially declared or after the property damages were assessed, insured people receive a compensation. As for people who are not insured against technological disasters, they get a compensation thanks to a guarantee fund.

- Complete review of the regulations regarding risk prevention:

For some industrial sectors, the regulation has been made tighter (for instance, the regulation regarding silos, pyrotechnics, organic peroxides, petrol stations...).

A national technical working group has been created at the end of 2008 to think about the ageing of industrial sites.

- New methodology for risk assessment and safety reports: Before 2003, risk assessment was based on the worstcase scenario. It was a deterministic approach. The law of July 30, 2003 now requires that the risk analysis takes into account the probability of occurrence, the kinetic and the gravity of potential accidents (article 4 of the law). It allows to assess precisely and objectively the acceptability of an industrial site in its environment. It can highlight the need for reducing the risks at the source, by cutting down the potientiel de danger (potential of danger), or reducing the probabilities of occurrence of the potential accidents and limiting the consequences through organizational and technical safety measures.

The lessons learned from other "probabilistic" regulations (for instance, the Dutch or the British regulations, the French regulation regarding the nuclear plants...) have proven extremely useful.

Then, in order to have a consistent implementation throughout the country, the following actions have been carried out:

- 21 technical working groups have been created between 2002 and 2003. They cover many industrial sectors or substances, such as ammonium nitrates, LPG, chlorine, ammonia, flammable liquids, pyrotechnics, refineries... Inspectors, policy advisers, representatives of operators and technical experts are members of these groups. Their goal is to harmonize the practices within a same industrial sector and to share experience between the inspectors and the operators. 
- A guideline describing the "General principles for the elaboration of safety reports" has been issued in 2006 (circular of December 28, 2006). It reviews all the elements that should be featured in a safety report. This circular makes also available other guidelines regarding for instance the human factor, the assessment of the gravity of an accident, BLEVE and UVCE in LPG units, etc.

- France's National Institute of Industrial Environment and Risks (INERIS) has published many scientific documents about the new risk assessment methodology. They are useful tools for both inspectors and operators.

The safety report is a key element, as its results are directly used for decision making. The government has indeed developed a risk matrix for assessing the societal acceptability of the risk generated by a Seveso establishment (circular of September 29, 2005). The input data are the probabilities of major accidents and the number of people potentially exposed to their consequences. The matrix (see figure 1 below) defines three levels of accidental risk:

- Acceptable (in white the matrix): the risk is acceptable.

- Unacceptable (in red): the risk is too important.

- ALARP (As Low As Reasonably Practicable, in yellow): the risk has to be reduced in order to become "as low as reasonably practicable".

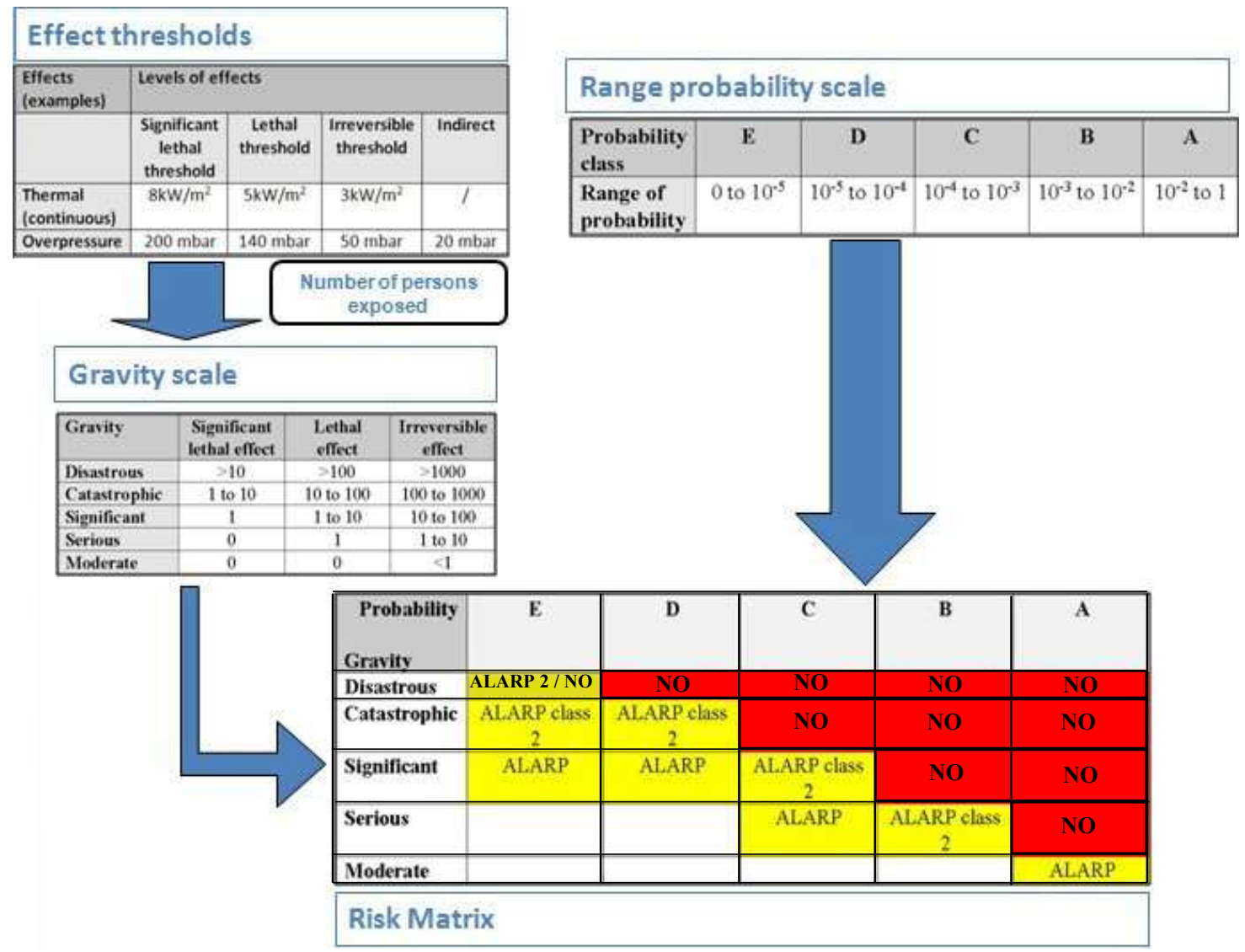

Fig. 1: A simplified risk matrix and its input data: effects thresholds, gravity and probabilities.

New and existing establishments are distinguished:

- New establishments are authorized if there is no accident in the red zone and if the operator proves that the best available technologies for both prevention and protection are used on the site.

- For existing establishments:

- If there is one accident (or more) in the red zone, the safety must be improved in order to reduce the gravity or the probability and, as a matter of fact, translate the accident in the yellow zone. If accidents still remain in 
the red zone in spite of an improvement of the safety, the establishment is liable to be closed by the Conseil $d^{\prime}$ Etat ${ }^{1}$.

- If there are accidents in the yellow zone, the operator has to add additional safety measures in order to reduce the risk as low as possible, given an acceptable cost/effectiveness ratio.

- If there is no accident in the red or yellow zones, the risk is considered as moderate provided the use of the best available technologies on site.

- Moreover, the law of July 30, 2003 involves safety reports for transport infrastructures where large quantities of dangerous goods can be momentarily in presence. The intended infrastructures are the sea- and river-ports, marshalling yards and important parking lots.

- Overhauling of the land-use planning policies: the Technological Risk Prevention plan (PPRT in French, standing for Plan de Prévention des Risques Technologiques) is one of the flag-ship measures of the law of July 30, 2003. The aim of the PPRT is to protect people by acting on the existing urbanization and also by controlling the future land-use planning in the vicinity of the existing top-tier Seveso establishments.

The whole process of the PPRT elaboration is carried out in cooperation between the local authorities, the operator, the CLIC representative and the residents. The lead-time is estimated at approximately 18 months. The most important stages are the following:

- Determination of the aléa $a^{2}$ by combining the probability of a dangerous phenomenon and the potential intensity of its effects. Aléas are calculated for each point of the territory and for each type of effects (thermal, overpressure and toxic effects).

- Analysis of the stakes in the vicinity of the establishment. The types if construction and public buildings are distinguished.

- Cross-reference of the aléas and the stakes, allowing to draw a zoning map.

The PPRT process is summed up on the following figure.

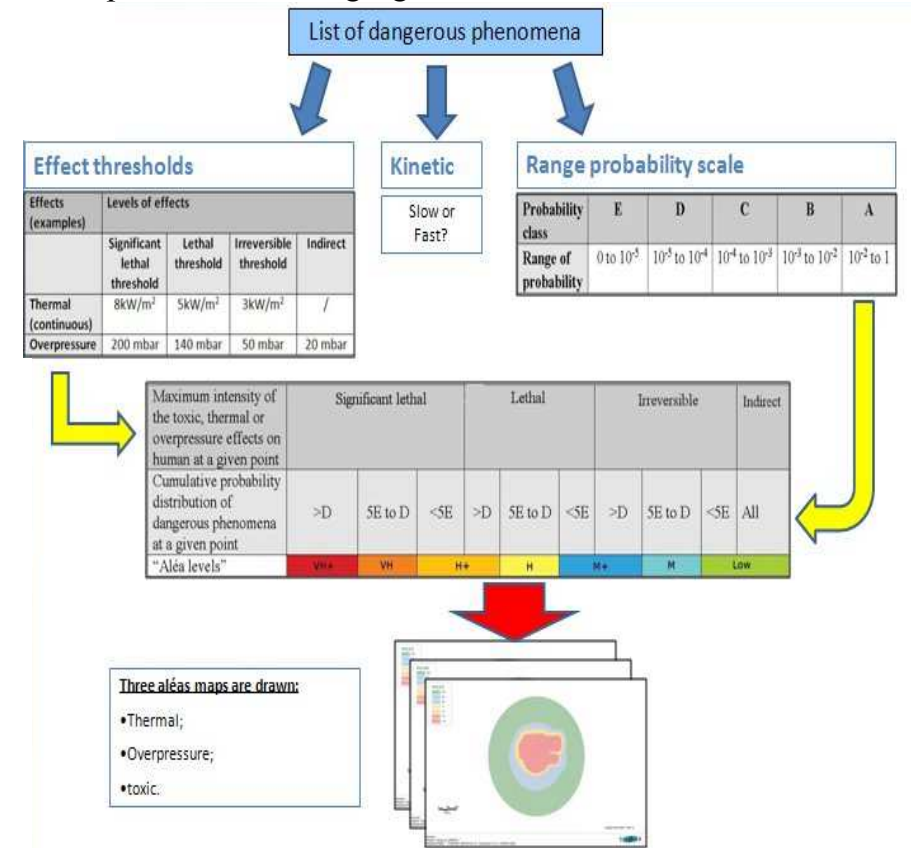

Fig. 2: Simplistic scheme presenting the elaboration process of a PPRT.

${ }^{1}$ The Conseil d'Etat is the highest level of the French administrative jurisdiction.

${ }^{2}$ Aléa: Probability that a dangerous phenomenon creates effects of a given intensity, and over a determined period of time at a given point of the territory. 
When the PPRT is finalized, it delineates a risk exposure perimeter, at the heart of which regulated zones are established. These zones can be either:

- "ban zones", within which future constructions are banned (red zones on the figure 2 below). Inside this zone, areas can be defined for expropriation (dark red areas on the figure 2 below) or relinquishments (dark or light red areas on the figure below).

- or "limitation zones", within which protective measures on the future or existing buildings can be compulsory (blue zones on the figure 2 below).

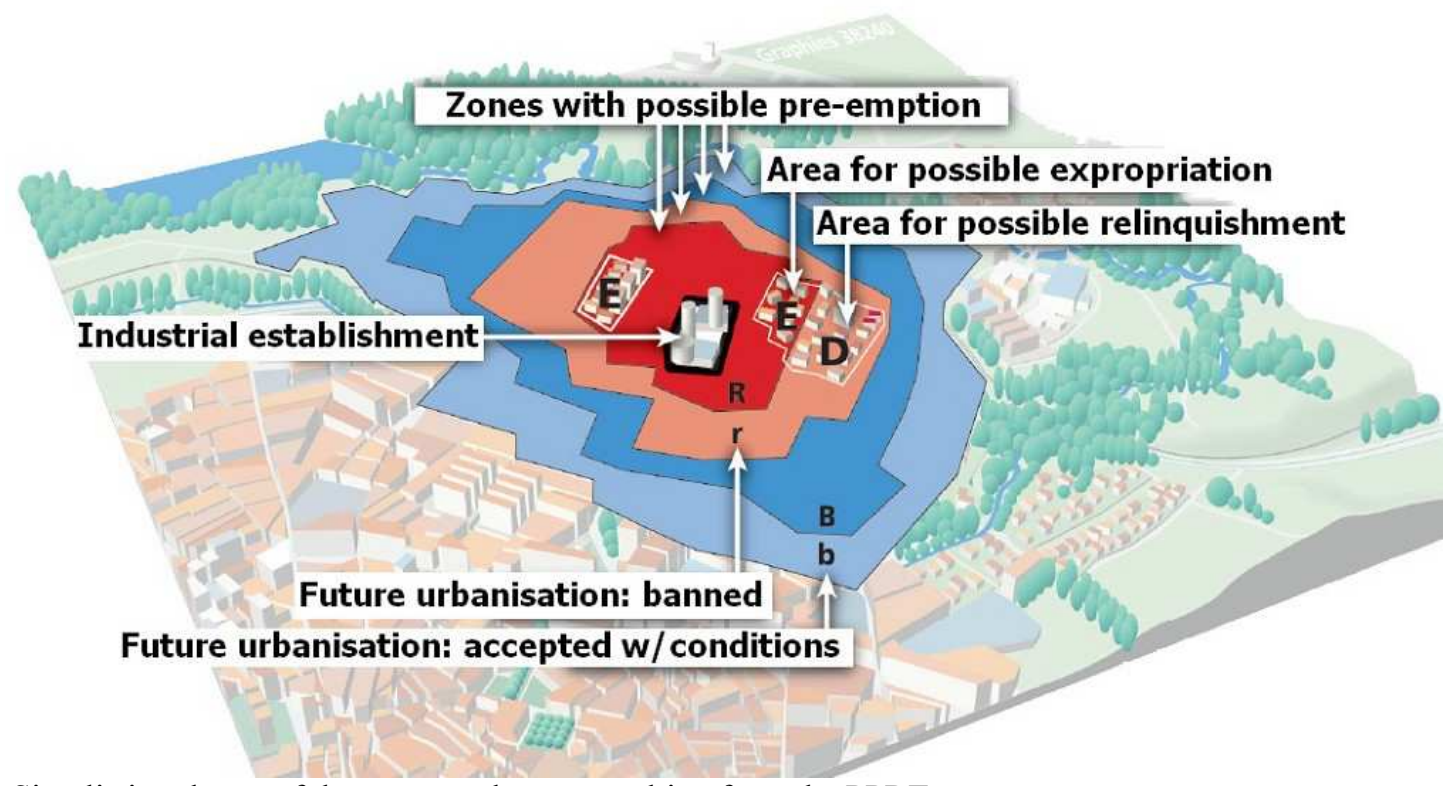

Fig. 3: Simplistic scheme of the zones and areas resulting from the PPRT process.

In total, in France, more than 400 industrial establishments or industrial parks (and 900 towns) are subject to a future PPRT. In July 2009, almost 200 PPRT are being finalized and 13 are approved.

The real-estate measures (expropriation and relinquishment) and additional risk reduction measures are evaluated to approximately 3 billion $€$. The financing of these measures is subject to a three-way financial agreement between the State, the operator and the local authorities.

The law of July 30, 2003 has hallowed the use of probabilities and frequencies into the French legislation and regulations regarding industrial risks. The risk analysis, at the heart of the safety report, has now to take into account the probability of occurrence, along with the kinetic, the gravity of the potential accidents. Then, combined with the gravity of potential accidents, the probability allows to assess the acceptability of an industrial establishment in its environment and the demonstration of risk control. As for land-use planning, probabilities are used for the calculation of the aléas, jointly required with an analysis of the stakes, for the elaboration of the PPRT.

\section{PROBABILISTIC ASSESSMENT METHODOLOGIES USED IN FRANCE IN COMPULSORY SAFETY REPORTS}

The French safety report comprises, among other things, a risk analysis and an assessment of major accident probabilities. In this second part, we will focus on the scenario identification realized through the risk analysis, on the methodologies used for assessing the reliability of safety barriers and on those used for assessing the central event frequencies. The methodologies and data used in order to assess the dangerous phenomenon from a central event frequency will be not detailed here. This includes in particular the use of ignition probabilities and meteorological data. 


\subsection{Scenario identification}

The use of probabilistic concepts has turned out to be very useful. All known possible scenarios are indeed identified, analysed and graded with regards to their probability of occurrence. The probability allows studying an exhaustive list of scenarios without focusing the analysis on low occurrence probability accidents that lead to large consequences.

Under the new regulation regarding risk prevention, an industrial operator has to identify all known and possible major accident scenarios, along with their prevention and mitigation barriers. Some of the risk analysis methodologies used are HAZOP, FMEA, Preliminary risk analysis...

This analysis is then followed by the assessment of the major accident probability, its kinetic and its potential consequences. The French regulation does not make compulsory a specific methodology, as long as the operator justifies his or her choice. The risk analysis usually identifies the possible central events (example: loss of containment) and their consequences (dangerous phenomena), but also, the initiating events leading to them. In order to present the results of this identification process, bow-tie diagrams have proven very useful. The figure 4 presents an example of a bow tie-diagram.

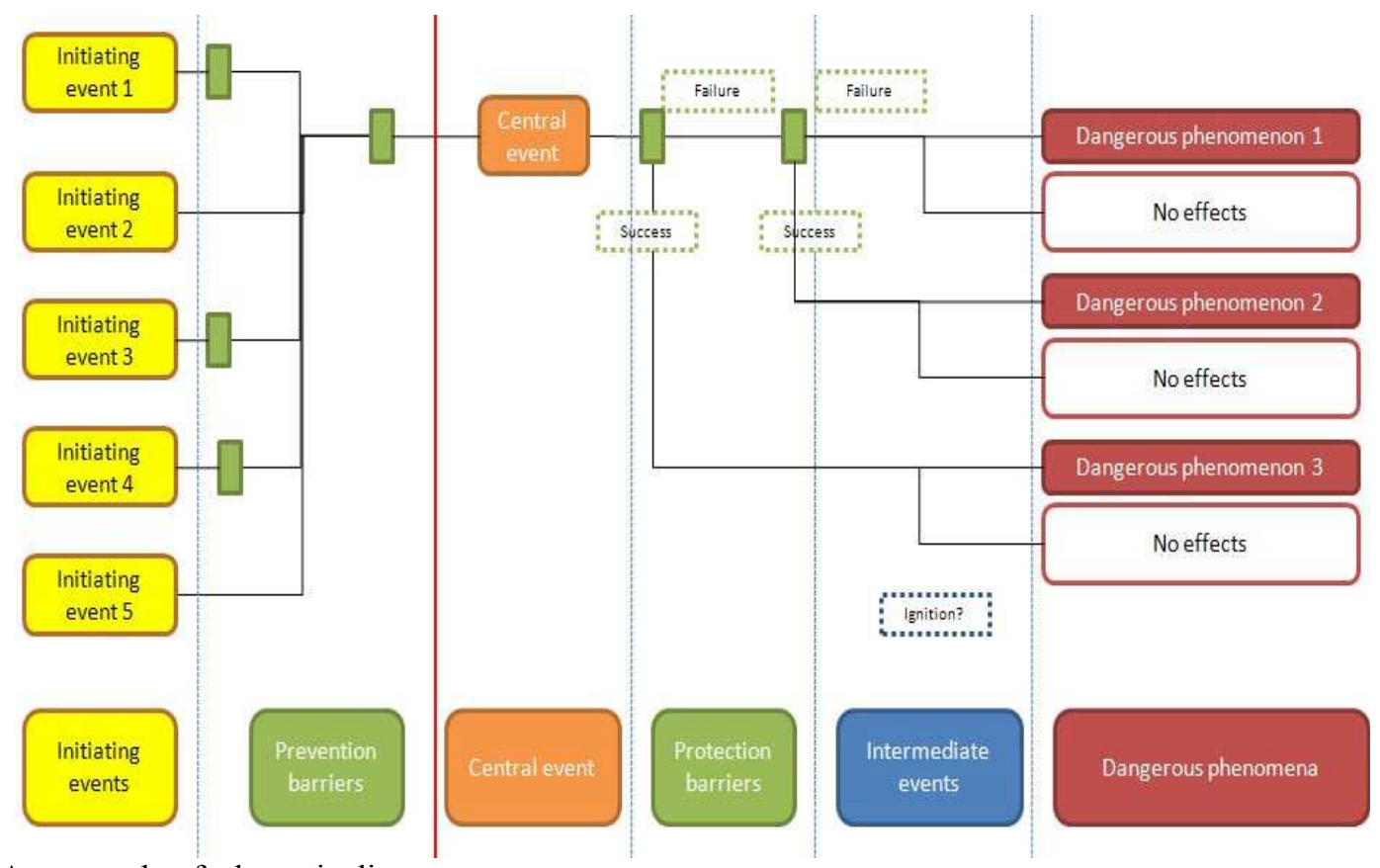

Fig. 4: An example of a bow-tie diagram

The bow-tie diagram is a combination of a simplified failure tree and an event tree. It is composed by initiating even1s in the left side of the diagram. Examples of initiating events could be a human error in a filling procedure, an impact resulting of a vehicle collision, a hammer effect... These initiating events lead to a central event which is often a loss of containment. Then, the central event leads to several dangerous phenomena such as BLEVE, boilover, pool fire, toxic cloud dispersion... Safety barriers may operate in prevention (before the central event) or in protection (after the central event). In the French regulatory framework, when protection barriers are considered, both the consequences of the success and the failure have to be assessed.

The probabilistic quantification of the scenarios is an important aspect of the safety report. Nevertheless, the qualitative identification of initiating events, central events, prevention and protection safety barriers and possible consequences realized through the implementation of the bow-tie diagram has to be considered also as a major step of the safety report. In terms of safety, this step noticeably improves the quality of the safety report. 
When the identification step is achieved, the ability of the barriers to prevent the occurrence of scenario or to limit the consequences has to to be evaluated.

\subsection{Safety barrier evaluation}

In a French safety report, the barrier analysis is a main issue for the demonstration of the risk control. For example, the permit (or the operating authorization) process introduces the ALARP (As Low As Reasonably Practicable) concept through a risk matrix (see the 2.3 part). As before-mentioned, if the risk is considered as unacceptable or ALARP, operators have the responsibility to implement additional safety measures or to bring the proof their safety system meet the ALARP requirements. Moreover, in the land use planning process, the scenarios selected in order to define land-use restriction and modifications are defined on the basis of the probability level and the barriers implemented on the facility.

Under the French regulation, three kinds of safety barriers have been identified: technical barriers, human barriers and barriers which gather both technical and human elements (see figure 5 hereunder).

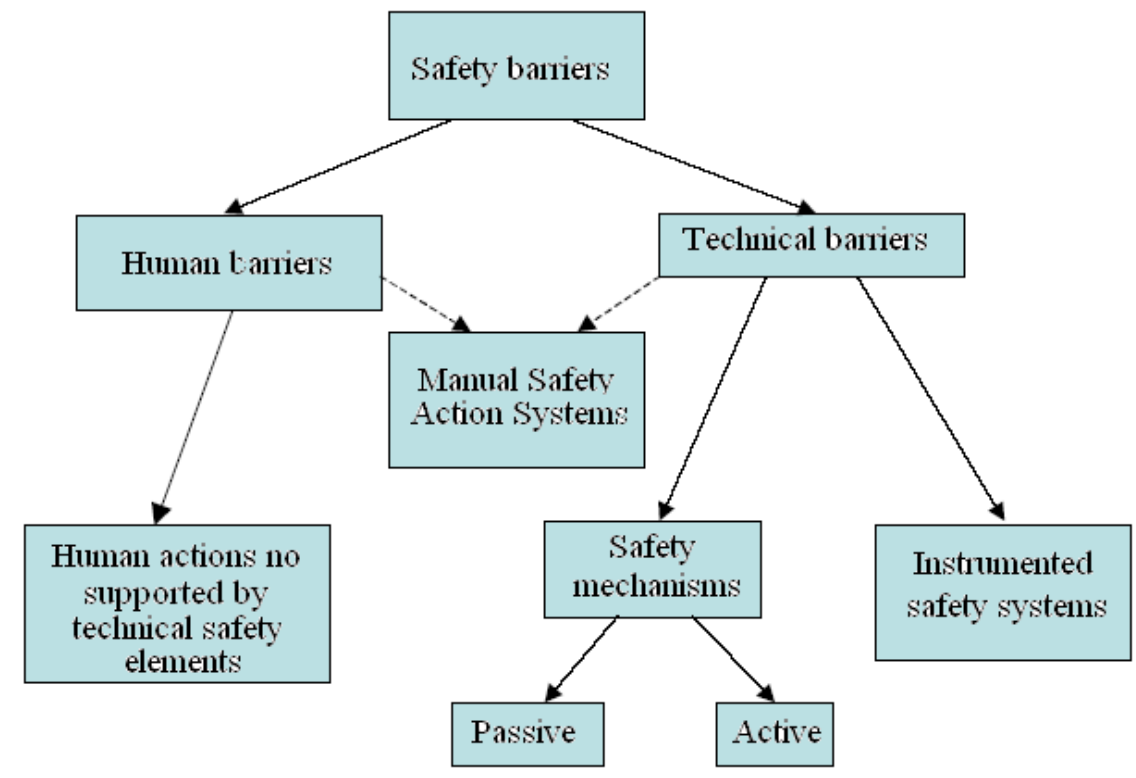

Fig. 5: Safety barrier typology (complementing the the typology presented in the $\Omega 10$ report (INERIS, 2005).

In order to be considered in the French regulatory framework, a safety barrier has to meet the following requirements. It has to $\mathrm{be}^{3}$ :

- Independent: the safety barrier must be independent of the cause of the scenario or of the scenario itself.

- Effective: able to fulfil the safety function that it was chosen for, in its usage context, for a period of operation process independent and independent of other safety barriers.

- With a response time in accordance with the kinetic of the scenario.

- Testable.

- Covered by preventive maintenance designed to guarantee that performance levels are maintained over time.

If these requirements are met, the safety barrier can be taken into account in the probabilistic quantification of a dangerous phenomenon. It reduces the occurrence frequency of a given scenario.

The question is then how does the failure probability of a barrier can be assessed, and so at which extend the presence of the barrier will reduce the frequency of a scenario. Actually, there are few data about the failure

${ }^{3}$ Definitions from the $\Omega 10$ and $\Omega 20$ reports (INERIS, 2005 and 2006). 
probability on-demand of a specific barrier. Moreover, the available data are generally an average of failure rates and are not applicable for a specific facility, in a specific environment.

In order to assess this value, INERIS has developed a methodology described in the $\Omega 10$ and $\Omega 20$ reports (INERIS 2005 and 2006). This methodology is illustrated by the figure 6 . The assessment is based on the evaluation of each component of the barrier with regards to three criteria: effectiveness (Eff), response time (RT) and level of confidence (LC). The level of confidence is then converted into a "risk reduction factor" (RR). The risk reduction factor represents by how much the presence of a given barrier would divide the frequency of a given scenario. For example, if there is a scenario with a frequency of $1.10^{-1}$ and a barrier with a risk reduction factor of 10 to prevent its occurrence, this means that the frequency of the event "occurrence of the scenario and failure of the barrier" is $10^{-2}$. In order to assess the risk reduction factor of the whole barrier, an aggregation of the data related to components is realised using a questioning process as described in the $\Omega 10$ and $\Omega 20$.

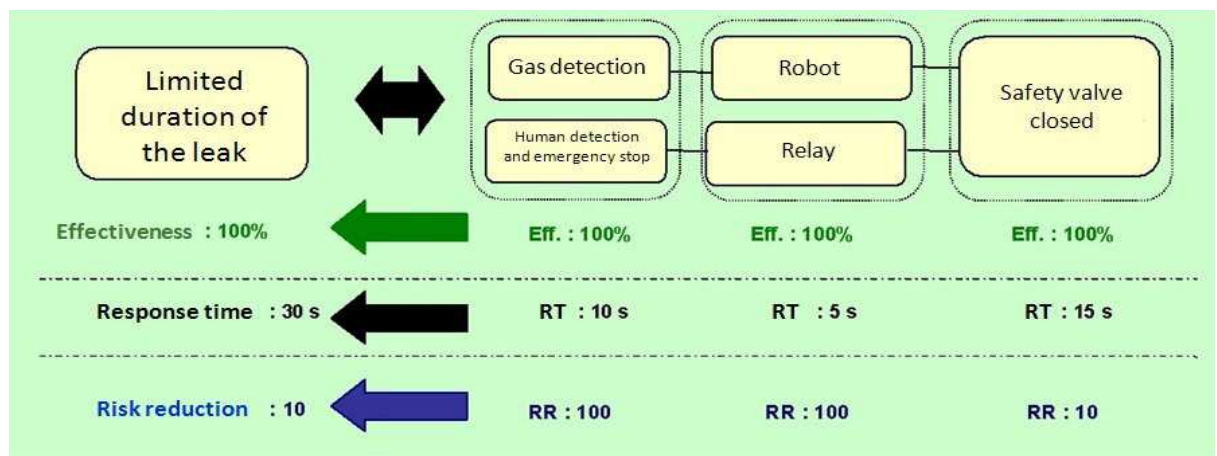

Fig. 6: An example of the assessment of a barrier according to the $\Omega 10$ methodology

The level of confidence, and so, the risk reduction factor of an active barrier is calculated using an extrapolation of SIL (Safety Integrity level) defined in the norms NF EN 61508 and NF EN 61 511. The approach described in these norms has been extended to all active barriers. Concerning passive barriers and human barriers, a maximum level of confidence has been defined through literature researches. The level of confidence is then reduced on the basis of different criteria (INERIS 2005 and 2006).

Most safety reports are based on this methodology in order to assess barriers. However, some other methodologies based on the use of reliability data are also used. In this last case, reliability databases such as OREDA and EIReDA are often used.

When all identified barriers are evaluated, the frequency of major accident can be assessed.

\subsection{Dangerous phenomena probability}

As operators are free to choose the methodology to be used in the safety report for assessing the occurrence probability of a dangerous phenomenon, the methodologies can be very different. Since 2005, two main methodologies have been used for major accident probability assessment:

- Quantitative evaluation "from the central event to dangerous phenomena";

- Quantitative evaluation "from initiating events to dangerous phenomena".

These two methodologies are approximately equally used.

The figure 7 presents these two methodologies. 


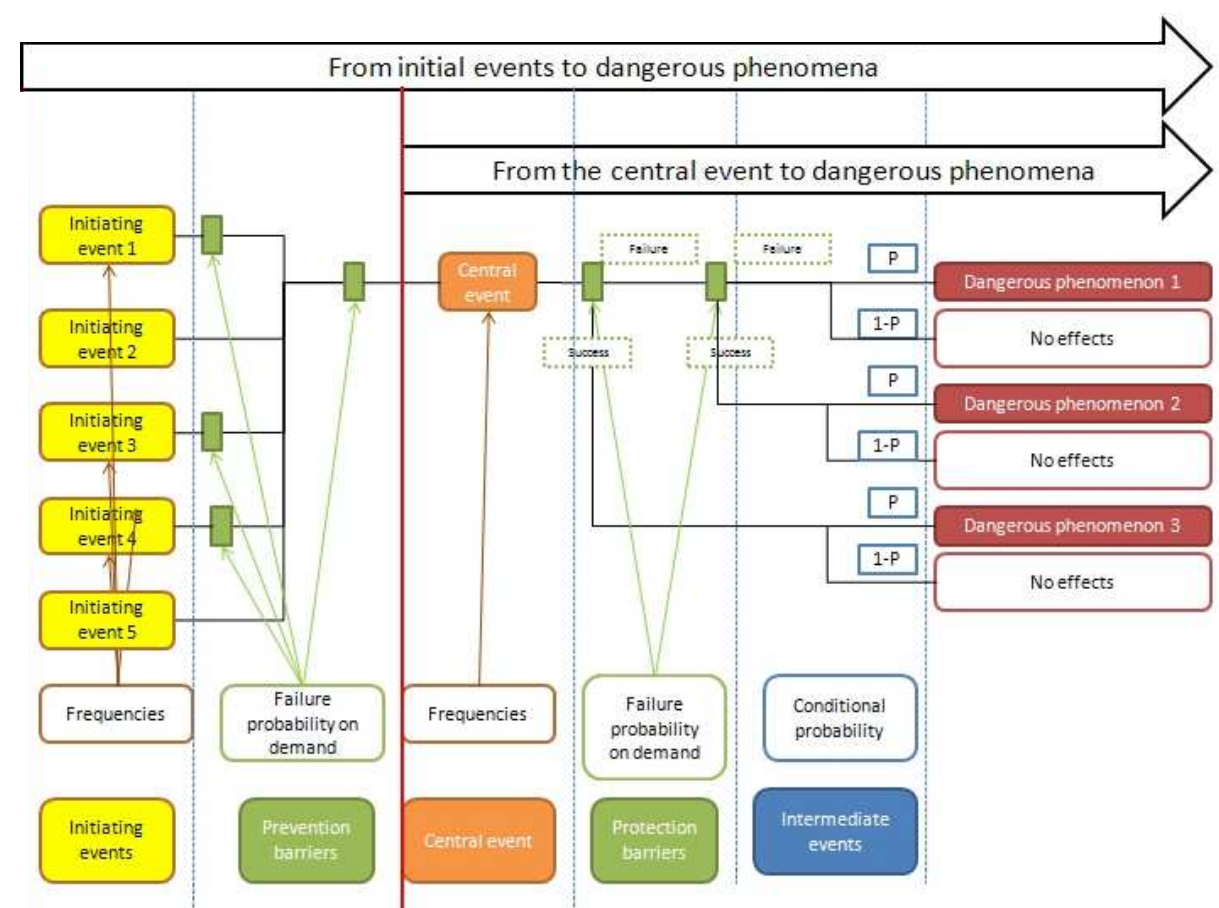

Fig. 7: The two mains methodologies used in France for the assessment of dangerous phenomena occurrence probability

In the following paragraphs, these two methodologies will be detailed together with their advantages and limits.

Quantitative evaluation "from the central event to dangerous phenomena":

This methodology is based on the quantification of event trees using Boolean algebra. The central event, which is often a loss of containment, is quantified using generic central event data. In France, data mainly comes from the Dutch "Purple book" (CPR 18 E, 1999) or from in-house operator database compiling and synthesizing generic data available in literature.

The main advantage of this methodology is its simplicity, both for the operator to set up and for the inspector to analyse. It also takes into account the activity volume of the facility (for example, for a hoses loss of containment, frequencies are expressed by hours of use) or the sizes of equipments (for example, for a pipes loss of containment, frequencies are expressed by meters).

On the other hand, this methodology has several limits. First, if the prevention of loss of containment is a major issue for the safety of an establishment, it is not taken into account into this methodology for the probabilistic assessment. Site specific aspects like specific lay-out, possible domino effects and specific environment are also neglected. Indeed, these data aim to express an average state-of-the-art of safety without consideration of local specificities. This methodology is indeed adapted to a work which focuses more specifically on limitation of consequences. Beyond limits related to the use of generic data, available generic data themselves present some imperfections:

- Generic central event frequencies are an expression of an average state-of-the-art safety in a given period. However, details on this state-of-the-art (design of equipments, norms and regulation in force...) are not always available. As a result, the exact applicability field of these data is generally unknown.

- When available, the applicability field can appear to be limited. Some of the data often used in France come from quite old studies. Examples could be frequencies derived from Bush (Bush, 1975) or Smith and Warwick (Smith and Warwick, 1981) studies. It can be also underlined that many of available data come from nuclear studies. Their applicability to the case of chemical plant is often unknown.

- A generally well accepted method used to balance the non-specific characteristic of generic data is the use of "correction factors". However, an accurate quantified evaluation of these factors implies a precise knowledge of the applicability field and distribution of causes linked to the loss of containment frequency. 
- Finally, data are not always available for all chemical facility equipments (example: data related to oil depot vapour treatment unit failures).

The good quality of central event occurrence data is, indeed, a major issue for the accuracy of the quantitative evaluation "from the central event to the dangerous phenomena". Unfortunately, although it has to be noticed that some data from recent studies are available for several equipments (example: oil open top floating roof tanks), good quality data are rare in the public domain.

Quantitative evaluation "from the initiating event to dangerous phenomena":

This methodology is based on the use of simplified failure trees and event trees. Two main approaches are used in order to estimate the frequency of initiating events.

A first one uses reliability data, or generic frequencies obtained by using reliability data. These data can be available for failure related to equipments. However, data related to human and organizational failures are very limited. A second one, used by INERIS, is the assessment of the frequencies through a questioning process applied to a working group (which could gather for example the risk manager of the facility, people from the maintenance, operators, etc.). Each initiating event is derived by the working group. They are expressed using frequency classes (frequency ranges). The table 1 presents the scale of frequency classes usually used.

\section{Table 1 Frequency classes used by INERIS in order to quantify initiating events}

\begin{tabular}{cc}
$\begin{array}{c}\text { Frequency } \\
\text { class }\end{array}$ & Failure frequency \\
\hline F-1 & Between 1 and 10 per year \\
F0 & Between $10^{-1}$ and 1 per year \\
F1 & Between $10^{-2}$ and $10^{-1}$ per year \\
F2 & Between $10^{-3}$ and $10^{-2}$ per year \\
F3 & Between $10^{-3}$ and $10^{-4}$ per year
\end{tabular}

Initiating events leading to a common central event are combined using AND and OR operators:

- If any of the initiating event can cause the central event, an OR operator is used. In that case, the frequency class of the central event is equal to the minimum frequency class of the initiating event;

- If multiple initiating events (and the frequency of these events are below $10^{-1}$ ) are required for the occurrence of the central event, an AND operator is used. In this case, the frequency class of the central event is equal to the sum of the frequency classes of the required initiating event;

- If a prevention barrier exists, the risk reduction factor of the barrier is added to the frequency class of the cause, which gives the frequency class of the intermediate event.

One of the more obvious advantages of this methodology is that it results from a deep analysis of the safety and of accident scenarios that could occur, their causes and barriers that prevent their occurrence. Therefore, site specific aspects (example: domino effects) and risk prevention issues are explicitly taken into account in probabilistic calculations. In this framework, operator's safety efforts are well promoted and their effectiveness is demonstrated qualitatively and quantitatively. The main possible causes of an accident are identified and graded in function of their frequency. The operator can, on this basis, target the future implementation of its prevention system.

As the methodology of the quantitative evaluation from the central event to the dangerous phenomenon, this methodology has numerous limits:

- At first, when frequency classes are used, the assessment does not aim to be as accurate as an assessment using frequency values. This implies an increase of uncertainties when there is a need for aggregating the probabilities of different dangerous phenomena;

- This methodology can take longer time to carry out. The identification and the quantification of multiple initiating events is a longer task than the definition and the quantification of a unique central event.

- Some initiating events are difficult to assess. This refers mainly to rare events that the working group have not observed in their facility or in similar facilities. An example of this could be an external impact on a pressure vessel. The frequency of some human errors may also be difficult to assess: distinguishing the occurrence of an initiating event from the occurrence of an initiating event together with the failure of a human prevention barrier may be 
difficult. In these cases, generic data on initiating events and reliability data can be used. However, when this solution is retained, the generic characteristic of the data implies several limits already presented above. An alternative way to assess the frequency of these events is the use of expert judgements. As for the methodology from the central event to the dangerous phenomena, the good quality of input data is also a main stake of the quality of the probabilistic assessment.

This second methodology fits better with the French regulation framework. Indeed, this framework gives the possibility to exclude from the societal risk assessment (MMR matrix related to permit to operate) and the land-use planning process a number of initiating events (earthquake, pressure vessel metallurgic default, aircraft crash...) if some conditions are respected. A probabilistic quantification "from the initiating events to the dangerous phenomena" allows taking into account these exclusions more easily than a probabilistic quantification "from the central event to the dangerous phenomena".

\subsection{Conclusions}

In the French regulatory framework, the ministry has proposed several guidelines for risk assessment. Nevertheless, the operator has the possibility to choose a general methodology in order to assess the reliability of barriers, the occurrence frequency of events and ultimately the occurrence probability of a major accident.

The probability of an accident is estimated by taking into account safety measures (barriers). The performance of safety barriers is evaluated with regards to the following criteria: independence, effectiveness, time response, testability and preventive maintenance. A methodology used in order to assess safety measures performance is described in the $\Omega 10$ and $\Omega 20$ reports (INERIS 2005 and 2006). Reliability analysis and data may also be used. These performances allow to decrease the occurrence frequency of initiating events (corrosion, works nearby a pipe, etc.) or of dangerous phenomena following the occurrence of a central event (loss of containment).

Concerning the assessment of event frequencies, two main methodologies are used by French operators. As before mentioned, they present advantages, but their main limit is the lack of good quality data.

\section{LESSONS LEARNED FROM THE USE OF PROBABILITIES}

Six years after the law of July 30,2003 , a first analysis of the main challenges of the use of probabilities is proposed hereafter.

\subsection{Site-specific frequency assessment}

Under the law of July 30, 2003 and the regulations resulting from it, an assessment of the frequencies of events is required. As each industrial site is different, uses various types of safety barriers and can be located in a different environment, this assessment has to be site-specific. As a demonstration, two refineries could be considered:

- One refinery dating from the 1960 s and located in the vicinity of the sea,

- The other refinery dating from the 1990s and located in an area without any oceanic influence.

It seems pretty obvious that the frequencies of initiating events, such as for instance corrosion, can not be equivalent. Likewise, if the newest refinery has multiple barriers, the frequency should aim to reflect it. This explains why the French national authorities promote a site-specific assessment.

Nevertheless, a certain homogeneity within a same industrial sector is required. In order to face up these difficulties, the 21 technical working groups, created after 2003, have proven very useful. They allow indeed operators, inspectors and experts to share their experience, and, as a matter of fact, can help harmonizing practices.

\subsection{Database gathering central event probabilities}


In relation with the importance of a site-specific assessment, databases gathering central event frequencies are not scientifically satisfactory. Such databases can not help to discriminate the good sites from the bad ones: neither the prevention safety barriers are taken into account, nor the age of the facility, the safety management... As a matter of fact, it renders difficult to focus on safety improvements and to make cost-effective investments, as many informations on a given scenario are missing. That is why the French authorities do not promote such methodologies.

\subsection{Low frequencies}

As before mentioned, in the French frequency scale, the smallest frequency class is $\left[0-10^{-5}\right]$. Frequencies lower than $10^{-5}$ happen to be not statistically and scientifically representative. In order to adjust this deficiency, two alternatives could be identified:

- Frequencies could artificially be increased, by a precautionary approach. No scientific analysis is then considered in this process.

- The range of magnitude of frequencies could be justified by taking into account the failure rates of safety barriers.

The second alternative has been chosen in France. As an illustration in the land-use planning, the PPRT does not take into account the most improbable dangerous phenomena, provided the following conditions (Circular of October 3, 2005 regarding the implementation of PPRTs) :

- Their probability has to be lower than $10^{-5}$.

- In order to be sure that the probability is not intrinsic of the phenomenon, it should take into account at least two technical safety barriers.

- In case of an increase of the probability of failure on-demand of any of the safety barriers, the probability has to remain lower than $10^{-5}$.

If all the above mentioned criteria are met, then the dangerous phenomena will not be taken into account for the land-use planning.

\section{CONCLUSIONS}

The law of July 30, 2003 has created very powerful tools regarding risk prevention, crisis management, communication to the public, involvement of employees and subcontractors and land -use planning.

Before 2003, only the worst-case scenarios were taken into account according to a deterministic approach. The law of July 30, 2003 has introduced the use of frequencies and probabilities into the French system. The safety report has now to describe accurately the probability of occurrence, along with the kinetic, the gravity of the potential accidents. Then, combined with the gravity of potential accidents, the probability allows to assess the acceptability of an industrial establishment in its environment and the demonstration of risk control. As for land-use planning, probabilities are used for the calculation of the aléas, jointly required with an analysis of the stakes, for the elaboration of the PPRT.

Several methodologies for risk assessment can be used (operator choice), but the French authorities favour the probabilistic quantification "from the initiating events to the dangerous phenomena": safety barriers are well taken into account (and the operator efforts are then better promoted) and it is site-specific. Moreover, for the land-use planning, it can be helpful to exclude some very rare dangerous phenomena.

More precise conclusions about the benefits and the challenges brought about by the use of frequencies and probabilities in French risk prevention policies will be available at the end of the whole PPRT process. 


\section{REFERENCES}

ARIA (2007). Explosion in a fertilizer plant - September 21 ${ }^{\text {st }}, 2001$ - Grande Paroisse Toulouse. http://www.aria.developpement-durable.gouv.fr. Sheet n²1 329,

Barthélémy, F., Hornus, H., Roussot, J., Hufschmitt J-P., Raffoux, J-F. (2001), « Usine de la société Grande Paroisse à Toulouse, Accident du 21 septembre 2001 ». Rapport de l'Inspection Générale de l'Environnement conjoint avec l'Inspection des Poudres et avec le concours de l'INERIS. Affaire nºIGE/01/034.

Bush, S.H. (1975), Pressure vessel reliability in Trans. of AMSE, Journal of Pressure Vessel Technology.

Circulaire du 29 septembre 2005 relative aux critères d'appréciation de la démarche de maîtrise des risques d'accidents susceptibles de survenir dans les établissements dits «Seveso » visés par l'arrêté du 10 mai 2000 modifié [Circular of September 29, 2005 regarding the evaluation criteria for the risk management process within Seveso establishments]

Circulaire du 3 octobre 2005 relative à la mise en œuvre des plans de prévention des risques technologiques [Circular of October 3, 2005 regarding the implementation of PPRTs].

Circular of December 28, 2006 making available the « General principles for the elaboration of safety reports » and the guidelines for the implementation of new regulations [Circular of December 28, 2006 making available the "General principles for the elaboration of safety reports » and the guidelines for the implementation of new regulations]

Committee for the Prevention of Disasters (CPR) (1999), Guidelines for Quantitative Risk Assessment—“Purple Book" CPR18E, SDU, The Hague.

Council Directive 96/82/EC of December 9, 1996 on the control of major-accident hazards involving dangerous substances.

Dechy, N., Mouilleau, Y. (2004). Damages of the Toulouse Disaster, $21^{\text {st }}$ September 2001. Loss Prevention and Safety Promotion in the Process Industries $-11^{\text {th }}$ International Symposium Loss Prevention 2004, $2353-2363$.

Décret impérial du 15 octobre 1810 relatif aux Manufactures et Ateliers qui répandent une odeur insalubre ou incommode [Imperial decree of October 15, 1810 regarding the factories that were sources of nuisances or risks]

INERIS (2005) $\Omega 10$, «Évaluation des dispositifs de prévention et de protection utilisés pour réduire les risques d'accidents majeurs », available on the website www.ineris.fr.

INERIS (2006), $\Omega 20$ «Démarche d'évaluation des barrières humaines de sécurité », available on the website www.ineris.fr.

INVS (2002). Suivi épidémiologique des conséquences sanitaires de l'explosion de l'usine AZF - Rapport intermédiaire.

Loi du 19 décembre 1917 relative aux établissements dangereux, incommodes ou insalubres. [Law of December 19, 1917 regarding the dangerous, unhealthy and inconvenient establishments]

Loi $\mathrm{n}^{\circ} 76-663 \mathrm{du} 19$ juillet 1976 relative aux installations classées pour la protection de l'environnement. [Law $n^{\circ} 76-$ 663 of July 19, 1976 regarding the classified installations for the protection of the environment]

Loi n²003-699 du 30 juillet 2003 relative à la prévention des risques technologiques et naturels et à la réparation des dommages. [Law $n^{\circ} 2003-699$ of July 30, 2003 regarding the prevention and repair of the damage caused by industrial and natural disasters] 
Ministry for Ecology, Energy, sustainable Development and the Sea (2008). Technological accidents inventory 2008.

NF-EN 61508 (March 2002), parts 1 to 7. Sécurité fonctionnelle des systèmes électriques/électroniques /électroniques programmables relatifs à la sécurité.

NF-EN 61511 (March 2005), parts 1 to 3. Sécurité fonctionnelle - Systèmes instrumentés de sécurité pour le secteur de l'industrie de process.

Procaccia, H., Arsenis S.P., Aufort P, Volta G. (1998). E S R e D A series on statistics: EIReDA European Industry Reliability Data Bank, Third Edition, Crete University Press.

SINTEF (2002), OREDA - Offshore Reliability Data, 4th Edition.

Smith T.A. and Warwick R.G. (1981). A survey of defects in pressure vessels in the UK for the period 1962-1978 and its relevance to nuclear primary circuits, UKAEA, SRD report R-203. 